\title{
Ethnic-Specific Associations between Abdominal and Gluteal Fat Distribution and the Metabolic Complications of Obesity: Implications for the Use of Liposuction
}

\author{
Philip Hayes ${ }^{1}$, Kevin Adams ${ }^{1}$, Joel A. Dave ${ }^{2}$ and Julia H. Goedecke ${ }^{3}$ \\ ${ }^{1}$ University of Cape Town (UCT), Grooteschuur Hospital, Department of Plastic and Reconstructive surgery, Cape \\ Town, South Africa \\ ${ }^{2}$ Endocrine Unit, Department of Medicine, UCT, South Africa
}

${ }^{3}$ South African Medical Research Council; UCT/MRC Research Unit for Exercise Science and Sports Medicine, Department of Human Biology, South Africa

Correspondence should be addressed to: Philip Hayes; pmhayeskzn@hotmail.com

Received 5 November 2012; Accepted 16 December 2012; Published 31 March 2013

Academic Editor: Ewa Wender-Ozegowska

Copyright (C 2013 Philip Hayes, Kevin Adams, Joel A. Dave and Julia H. Goedecke. Distributed under Creative Commons CC-BY 3.0

\begin{abstract}
Adipose tissue is now considered to be an endocrine organ. Ever since this realization, there has been much debate on the effectiveness of liposuction to improve insulin sensitivity (IS) and the metabolic profile. To examine the ethnic and physiological differences of abdominal and gluteal fat compartments and their relationship to IS. Body composition, fat distribution, IS and serum; lipids, adipokines and inflammatory mediators were measured in fifty-four healthy, premenopausal women. Biopsies were taken from subcutaneous fat depots to measure leptin, adiponectin and IL-18 mRNA levels. Obese black women had more superficial subcutaneous abdominal (SAT) $(\mathrm{p}<0.01)$ and gluteal $(\mathrm{p}=0.043)$, but less visceral adipose tissue $(\mathrm{VAT})(\mathrm{p}<0.05)$ than their white counterparts. Nonetheless, black women were less insulin-sensitive than white women $(\mathrm{p}<0.01)$. IS correlated with deep and superficial SAT $(\mathrm{p}<0.01)$ in both ethnic groups but gluteal fat was inversely associated with IS only in black women (black $p=0.033$, white $p=0.22)$. IL-18 mRNA $(p<0.001)$ and leptin mRNA levels $(p<0.001)$ were highest in gluteal fat than abdominal fat depots in both ethnic groups. Obese black women had more SAT than obese white women. SAT area correlated inversely with IS in both races, whereas the gluteal fat mass in black women and VAT in white women were associated with decreasing IS, respectively. Both lean and obese black South African women were more insulin resistant than their white counterparts. We therefore hypothesize that reduction in SAT (in both races) and gluteal fat mass (only in black women) may beneficially improve the IS and metabolic profile.
\end{abstract}

Keywords: Obesity, CV risk- cardiovascular risk, metabolic complications of obesity (MCO), insulin sensitivity (IS), large volume liposuction (LVL).

Cite this Article as: Philip Hayes, Kevin Adams, Joel A. Dave and Julia H. Goedecke (2013), " EthnicSpecific Associations between Abdominal and Gluteal Fat Distribution and the Metabolic Complications of Obesity: Implications for the Use of Liposuction," Plastic Surgery: An International Journal, Vol. 2013 (2013), Article ID 796359, DOI: 10.5171/2013.796359 


\section{Introduction}

Obesity is an epidemic of the $21^{\text {st }}$ century and is aetiologically associated with a host

of medical conditions (including type 2 diabetes mellitus and cardiovascular disease) and even certain cancers (as reported by numerous authors including Bays et al. (2008) and Hamad et al. (2004)). Although the association between obesity and these diseases is well established, the mechanisms through which obesity results in disease are less understood. Greenberg and Obin (2006) stated the fundamental shift in our understanding is that adipose tissue is not a simple energy storage devise but an endocrine organ is of paramount importance.

Lago et al. (2007) and Bays (2009) suggest that in obesity, hypertrophic truncal adipose tissue has a deranged function and secretes a variety of substances, including abnormal amounts of adipokines, free fatty acids and chronic inflammatory mediators. This results in increased insulin resistance (IR), dyslipidaemia and essential hypertension and promotes the development of type 2 diabetes mellitus, atherosclerosis, cardiovascular disease and ultimately premature death.

According to Finucane et al. (2011), current public health initiatives have failed to reverse the obesity epidemic. It would therefore be desirable to intervene and remove the 'sick truncal fat' (term used by Bays (2009)) to curb the pathophysiological deterioration and potentially preventing the development of type 2 diabetes and the cardiovascular complications of obesity. Accordingly, there has been much debate regarding the effectiveness of liposuction as a means of improving insulin sensitivity (IS) and the metabolic profile. Several prospective clinical trials have been performed examining the effects of large volume liposuction (LVL) on IR, dyslipidaemia, inflammatory mediators and hypertension (see table 1 in addendum). The results of these trials are however conflicting.

Approximately $75 \%$ of the quoted studies (table 1), which represent 88.6\% (233/263 patients) of the total number of patients studied, showed a statistically significant improvement in IS and the metabolic profile in both overweight (body mass index (BMI) $>25 \mathrm{~kg} / \mathrm{m}^{2}$ ) and obese (BMI $>30 \mathrm{~kg} / \mathrm{m}^{2}$ ) non-diabetic women. In contrast, the studies by Klein et al. (2004, 2008) and Robles-Cervantes et al. (2004) showed no significant improvement in the metabolic profile. These authors, as well as Kelly (2004), suggested that the liposuction was purely cosmetic and that loss of weight, by dieting and exercise, was needed to improve the metabolic profile. 


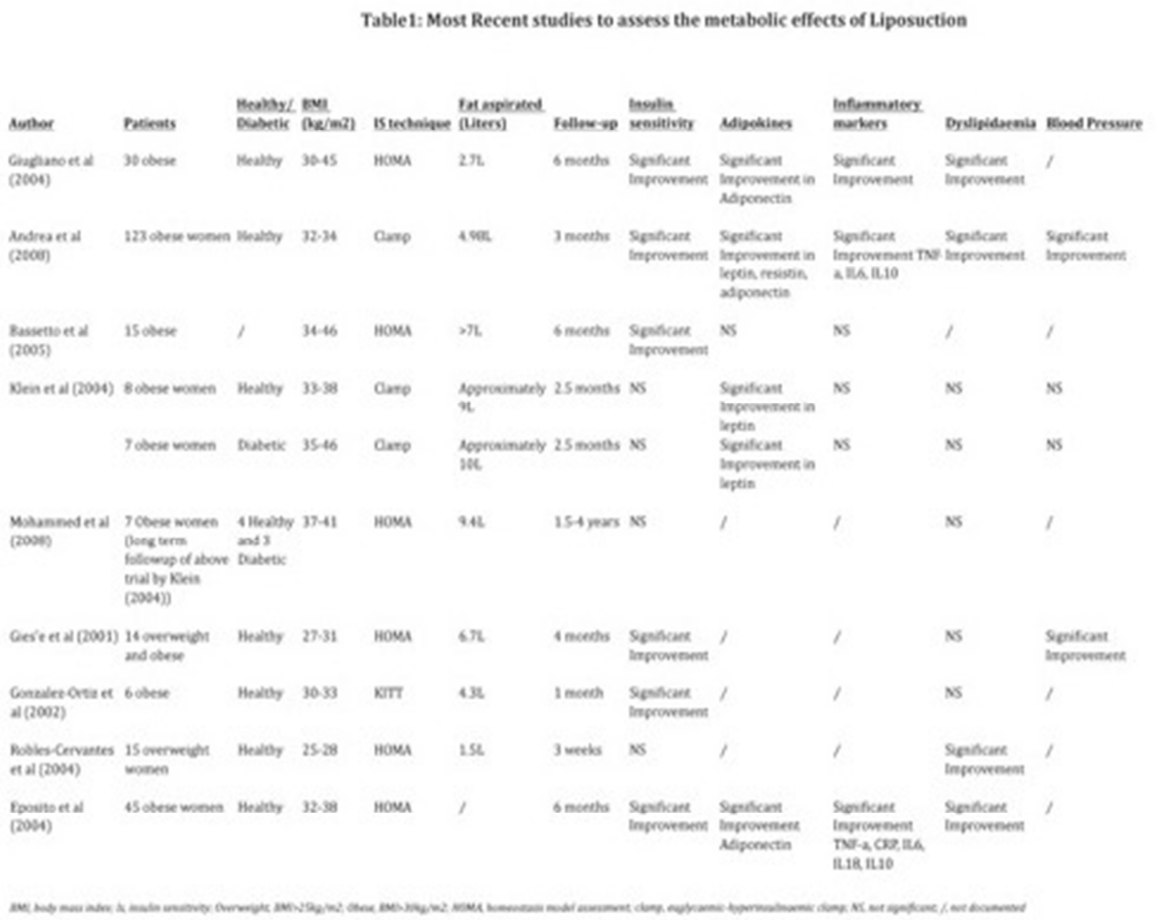

There are several reasons that could account for these conflicting results. For example, the majority of the studies had very small patient population sizes (less than 15) with the clinical status of the patients varying from healthy to diabetic. In addition, the technique used to measure IS and the duration of follow-up varied significantly between trials. Additional factors that could influence the outcome of a trial examining the metabolic effects of LVL are the site and volume of fat removed as the metabolic activity and profile of regional fat depots varies (as demonstrated by Goedecke, 2009).

In this regard central obesity, measured by an increased waist circumference (male $>102 \mathrm{~cm} / 40$ inches, females $>88 \mathrm{~cm} / 35$ inches), has consistently been associated with an increased risk of diabetes and cardiovascular disease independently of total adiposity, as measured by BMI (studies by Carey, 1996; Wei, 1997; Janssen, 2004 and Klein, 2004). The central fat depot however includes contributions from the retroperitoneal and intra-abdominal fat (or visceral adipose tissue (VAT)) as well as the subcutaneous abdominal adipose tissue (SAT). Several studies including the continuation of 'The Framington Heart study' by Preis et al. (2010), have shown that both VAT as well as SAT are directly correlated with the metabolic risk factors for cardiovascular disease and insulin resistance. However, only the volume of SAT, not VAT, can be easily reduced surgically via liposuction.

SAT is further divided into the superficial subcutaneous abdominal adipose tissue (SSAT) and the deep subcutaneous abdominal adipose tissue (DSAT) by Scarpa's fascia. The fat in these two subcutaneous compartments are histologically distinct. Perez (2007) showed that the DSAT contains more loosely distributed fascial septae with larger, more irregularly distributed fat lobules, versus the SSAT with its compact fascial septae and small tightly-packed fat lobules.

Studies, such as Coleberg et al. (1995) and Barzalai et al. (1999), initially suggested that the increased volume of VAT, which is closely related to the liver and pancreas, was responsible for the MCO. Numerous studies (studies by Abate et al., 1995; Goodpaster et al., 1997.; Goedecke et al., 2006 and Walker et al., 2007) have however shown that DSAT is equally, if not more closely correlated with the 
development of essential hypertension, dyslipidaemia, impaired fibrinolysis, raised IR and increased cardiovascular risk (CV risk) than VAT volume.

The relationship between SSAT and this metabolic risk is however less clear. Misra et al. (1997) and Kelly et al. (2000) believe that SSAT accumulation is not associated with MCO, and may even be protective. Other authors (including Abate et al. (1995 \& 1996) and Goodpaster et al. (1997)) using similar study techniques but larger population samples, have found that SSAT behaves similarly to DSAT and VAT with respect to metabolic risk. However, as the association of SSAT with MCO is not clearly established, lipectomy of SSAT (which occurs invariably during liposuction) could either improve or worsen the metabolic profile. Further research is therefore needed to clarify SSAT role in obesity.

Another explanation for the conflicting results of these SSAT studies, as well as for the conflicting results of the studies examining the metabolic effects of LVL, is the influence that ethnicity has on the metabolic activity of the regional fat depots.

In this regard Libovitz and Banerji (2005) showed that Asian Indians with the same body fat and distribution as Caucasians have increased: IR, free fatty acids (FFA), Creactive protein (CRP), plasminogen activator inhibitor-1 (PAI) and decreased adiponectin. Similarly, a recent multicentre international study by Nazare et al. (2012) found that ethnic differences in cardiometabolic risk are related to ethnic specific patterns of body fat distribution. In the African context, obese black women are phenotypically different to obese white women. Lovejoy et al. (1996) found that Caucasian women accumulate more fat centrally compared to their African/ black counterparts, who accumulate more gluteofemoral and subcutaneous adipose tissue (SAT), and develop prominent steatopygia. Two studies by Punyadeera et al. (both in 2001), found that black women have significantly less VAT than white women. Despite such findings, Joffe et al. (1994), Schutte et al. (2008) and Seedat et al. (1983) demonstrated that obese black Southern African women have double the prevalence of diabetes $(7.0 \%$ vs. $3.6 \%)$ and hypertension $(30 \%$ vs. $15 \%)$ compared to obese white women who are more commonly present with coronary heart disease and hypercholesterolaemia.

This suggests that SAT volume in black women may be more strongly correlated with the development of IR than in white women. Thus, obese black women may benefit more metabolically from a reduction in SAT volume (by for example liposuction) than obese white women.

Therefore the aims of the study are:

1. To determine the ethnic specific (black vs. white) variations in fat distribution of lean compared to obese South African women.

2. To determine the ethnic specific associations of these fat depots with insulin resistance (especially SSAT which is the least investigated fat depot with regard to metabolic risk).

3. To determine the ethnic variations in the expression of adipokines and inflammatory markers in each of the fat depots and their associations with IS.

\section{Methods}

\section{Subjects}

Fifty-four South African women were recruited by advertisement in local newspapers and from local church groups, community centers and universities. The study population consisted of 14 normalweight (body mass index [BMI] 18-25 $\mathrm{kg} / \mathrm{m}^{2}$ ) black, 13 normal- weight white, 14 obese (BMI $>30 \mathrm{~kg} / \mathrm{m}^{2}$ ) black, and 13 obese white South African women.

Inclusion criteria were as follows:

(1) age from 18 to 45 years; (2) no known diseases or taking medication for dyslipidemia, diabetes, hypertension, HIV/ AIDS, or any other metabolic disorders; (3) not currently pregnant, lactating, or postmenopausal; and (4) of South African ancestry. The study was approved by the Human Research Ethics Committee of the Faculty of Health Sciences of the University 
of Cape Town. Before participating in the study, procedures and risks were explained to the subjects, all of whom gave written informed consent to participate in the study. This study is a continuation of research from our previously published work (Goedecke, 2009).

\section{Study Design}

\section{Body Composition and Blood Pressure Measurement}

Basic anthropometric measurements including weight, height and waist (at the level of the umbilicus) and hip (largest gluteal area) circumference were taken. Body fat percentage and the gynoid region of interest (as per Ley et al.'s description (1992)) were measured using dual-energy x-ray absorptiometry (Discovery-W, Software version 4.40; Hologic, Bedford, MA) the measurement of which has a coefficient of variation of $1.7 \%$. Abdominal visceral (VAT) and subcutaneous adipose tissue (SAT) area was measured at the level of L4-L5 lumbar vertebrae using computed tomography (Toshiba X-press Helical Scanner, Tokyo, Japan). The fascia superficialis was used to distinguish between the deep (DSAT) and superficial (SSAT) SAT depots.

Blood pressure was measured in a seated position after 5-10 minutes of rest using an automated blood pressure monitor (Omron 711; Omron health Care, Hamburg, Germany). The average of three measurements taken at 1 minute intervals was used in the analysis.

\section{Measurement of Glucose Tolerance, Insulin Sensitivity and Insulin Release}

After an overnight fast, a blood sample was taken for the determination of fasting plasma glucose, serum insulin, lipids, adiponectin, leptin, high-sensitivity Creactive protein (CRP) levels and interleukin-18 (IL-18). Subjects then underwent an insulin-modified frequently sampled intravenous glucose tolerance test (FSIGT) to quantify insulin sensitivity. Baseline samples were drawn at $-15,-5$, and -1 minutes before the infusion of glucose $(50 \%$ dextrose; $11.4 \mathrm{~g} / \mathrm{m} 2$ body surface area) over 60 seconds at time 0 . At 20 minutes, human insulin $0.02 \mathrm{U} / \mathrm{kg}$; Actrapid, Novo Nordisk, Sandton, South Africa) was infused over 5 minutes at a constant rate (i.e. a slow bolus of insulin). Plasma glucose and serum insulin concentrations were measured in the 3 baseline samples and the 32 samples drawn over 240 minutes after commencement of the glucose infusion. Glucose and insulin data from the FSIGT were used to calculate the insulin sensitivity index (IS) using the minimal model of glucose kinetics of Bergman et al. (1979). The samples were centrifuged at $3000 \mathrm{rpm}$ for 10 minutes at $4^{\circ} \mathrm{C}$, the plasma was stored at $-20^{\circ} \mathrm{C}$ for subsequent analysis of glucose concentrations, and the serum was stored at $-80^{\circ} \mathrm{C}$ for the subsequent analysis of insulin concentrations.

\section{Biochemical Analysis}

Plasma glucose concentrations were determined using the glucose oxidase method (YSI 2300 STAT PLUS, YSI Life Sciences, Yellow Springs, OH). Serum insulin concentrations were determined by immunochemiluminometric assays using the ADVIA Centaur (Bayer Diagnostics, Tarrytown, NJ). The intra- and interassay coefficients of variation for plasma glucose and serum insulin concentrations were 0.6 and $2.5 \%$, and 4.5 and $12.2 \%$, respectively.

Blood lipids were analyzed using the Roche Modular autoanalyzer (Penzberg, Germany). Enzymatic colorimetric assays were used to analyze total cholesterol, triglyceride and HDL cholesterol concentrations. The LDL cholesterol concentrations were determined using the Friedewald formula.

Serum concentrations of leptin (Linco Research, St Charles, Missouri, USA), high molecular weight (HMW) adiponectin (Linco Research, St Charles, Missouri, USA), high sensitive C-reactive protein (hsCRP, Immun Diagnostik AG, Bensheim, Germany) and IL-18 (BioSource Europe S.A., Nivelles, Belgium) were all analyzed using commercially available ELISA kits 
according to the manufacturer's protocols.

\section{Fat Harvest Technique}

On a separate day and after a 4-hour fast, fat biopsies were obtained from the abdominal DSAT, SSAT and gluteal areas, using a mini-liposuction technique. After local anaesthesia with Lignocaine hydrochloride $(2 \%, \quad$ Intramed, Port Elizabeth, South Africa), a small incision was made directly above the umbilicus. 200-300 $\mathrm{ml}$ of normal saline with adrenaline $(0.1 \%$, Intramed, Port Elizabeth, South Africa) and Lignocaine $(0.75 \%$, Intramed, Port Elizabeth, South Africa) was infused using an infiltration cannula (Lamis 14ga x 15cm, Byron Medical Inc., Tucson, AZ). An aspiration cannula (Coleman, 12ga $\mathrm{x} 15 \mathrm{~cm}$, Byron Medical Inc, Tucson, AZ) attached to a $10 \mathrm{ml}$ syringe was used to aspirate fat from above (SSAT) and below (DSAT) the fascia superficialis, under ultrasound guidance by a radiologist. Gluteal samples were obtained from the right upper quadrant using the same procedure. Approximately $2 \mathrm{ml}$ of fat was extracted from each site and washed three times with normal saline or until no blood was visible. AT was then placed into vials and frozen immediately in liquid nitrogen and stored at $-80^{\circ} \mathrm{C}$ for subsequent analyses.

\section{Quantification of Mrna by Real-Time Quantitative PCR}

Total RNA was extracted from snap-frozen tissue samples using the Qiagen RNeasy system, and 500ng reverse transcribed into cDNA with random primers using the QuantiTect DNase/reverse transcription kit (Qiagen Ltd, Crawley, UK). cDNA (equivalent to 1 ng total RNA) was

incubated in triplicate in $1 \mathrm{x}$ Roche LightCycler®480 Probes master mix (Roche Diagnostics Ltd, Burgess Hill, UK) with gene specific primers (Invitrogen Ltd, Paisley, UK). A standard curve was constructed for each primer probe set using a serial dilution of cDNA pooled from all samples. The NormFinder algorithm identified a combination of PPIA, 18S and
RPLPO as the best normalization gene set, with expression levels not being altered by obesity, ethnicity or depot. Results are presented as the ratio of abundance of gene of interest: mean of abundance of PPIA, $18 \mathrm{~S}$ and RPLO.

\section{Statistics}

Results are presented as means \pm standard error. Two-way analysis of covariance adjusting for age was used to compare anthropometric and metabolic measures between normal-weight and obese, black and white women, with Bonferroni post hoc analyses. Ethnic differences in abdominal adipose tissue depots were also adjusted for total fat mass. Data were normalized by log transformation, if required. Pearson correlation coefficients were used to explore the relationships between body composition and metabolic outcomes.

Differences in mRNA levels between ethnicity and BMI groups within each SAT depot were analysed using two-way ANOVA, adjusting for age, with Bonferroni post hoc analysis. Repeated measures ANOVA, with Tukey post hoc analysis, was used to determine depot differences in gene expression. Partial correlations, adjusting for age and fat mass, were used to explore the associations between gene expression and measures of insulin sensitivity in both black and white women. Data were analyzed using STATISTICA version 10 (Statsoft Inc., Tulsa, OK).

\section{Results}

The obese women were significantly older than the normal weight women (mean of 29 years vs. 25 years) (Table 2). Consequently, all subsequent analyses were adjusted for age.

\section{Body Composition}

By design, all measures of body composition and regional fat deposition were significantly greater in the obese than the normal-weight women (Table 2). The lean and obese black and white groups 
were well matched for BMI and total adiposity

$$
\text { (dual-energy X-ray }
$$

Table 2. Body composition and distribution absorptiometry derived fat mass and \% body fat).

\begin{tabular}{|c|c|c|c|c|}
\hline & $\begin{array}{l}\text { Lean Black } \\
\qquad(n=14)\end{array}$ & $\begin{array}{l}\text { Lean White } \\
\qquad(n=13)\end{array}$ & $\begin{array}{l}\text { Obese Black } \\
\qquad(n=14)\end{array}$ & $\begin{array}{c}\text { Obese White } \\
\qquad(n=13)\end{array}$ \\
\hline Age (yrs) & $23 \div 2$ & $25 \div 2$ & $28 \pm 2$ & $32 \div 2$ \\
\hline BMI $\left(\mathrm{kg} / \mathrm{m}^{2}\right)$ & $22.9 \pm 1.0^{c}$ & $22.6 \div 1.0^{5}$ & $37.9 \div 1.0 \mathrm{c}$ & $36.5 \pm 1.0^{\circ}$ \\
\hline Fat mass (kg) & $17.2+1.9 c$ & $18.9 \div 2.0^{\circ}$ & $43.6 \pm 1.9 c$ & $45.6 \pm 2.0^{\circ}$ \\
\hline Body fat (\%) & $30.4 \pm 1.3 c$ & $29.4 \pm 1.4^{\circ}$ & $47.2 \pm 1.3 c$ & $45.3 \pm 1.4^{\circ}$ \\
\hline \multicolumn{5}{|c|}{ Regional body fat distribution } \\
\hline Waist $(\mathrm{cm})$ & $76.2 \pm 2.86$ & $79.7+2.90$ & $113.0 \pm 2.8$ & $1083 \pm 2.90$ \\
\hline Hip (cm) & $98.4 \pm 2.4 \mathrm{C}$ & $102.0 \div 2.4^{\circ}$ & $126.1 \pm 2.4 c$ & $125.3 \pm 2.4^{\circ}$ \\
\hline WHR & $0.78 \pm 0.02 c$ & $0.78 \div 0.02^{\circ}$ & $0.90 \pm .02^{c}$ & $0.86 \div 0.02^{\circ}$ \\
\hline $\operatorname{VAT}\left(\mathrm{cm}^{2}\right)$ & $60.4 \pm 10.9 c$ & $56.7 \div 10.9^{\circ}$ & $98.4 \div 11.3^{2} c$ & $147.2 \div 11.8^{n 0}$ \\
\hline Deep SAT $\left(\mathrm{cm}^{2}\right)$ & $68.0 \pm 14.5 c$ & $83.3 \div 14.5^{\circ}$ & $264.6 \pm 15.1^{c}$ & $257.6 \pm 15.8^{\circ}$ \\
\hline Superficial SAT $\left(\mathrm{cm}^{2}\right)$ & $980 \pm 14.2^{c}$ & $95.2 \div 14.2^{\circ}$ & $325.1 \pm 14.8^{\circ \mathrm{C}}$ & $247.3 \pm 15.4^{20.0}$ \\
\hline Total SAT $\left(\mathrm{cm}^{2}\right)$ & $176.7 \pm 22.3 c$ & $175.5 \pm 20.70$ & $591.3 \pm 21.4 \mathrm{cc}$ & $492.2 \pm 21.4^{n d}$ \\
\hline Gynoid fat (kg) & $1.76 \pm 0.18$ & $1.70 \div 0.18$ & $4.09 \div 0.18$ & $3.54 \div 0.20^{\circ}$ \\
\hline \multicolumn{5}{|l|}{ Blood Pressure } \\
\hline Systolic $\left(\mathrm{mmHg}_{\mathrm{g}}\right)$ & $104 \pm 4$ & $110 \div 4$ & $110 \pm 4$ & $112 \div 4$ \\
\hline Diastolic (mmHg) & $69 \pm 2 c$ & $70 \div 2^{\circ}$ & $77 \div 2 c$ & $76 \pm 2^{D}$ \\
\hline
\end{tabular}

Values are unadjusted mean \pm SEM. All $P$ values adjusted for age.

a $P<0.05$ and $A P<0.01$ : Lean black vs. Lean white.

$b P<0.05$ and $B P<0.01$ : Obese black vs, obese white.

$c P<0.05$ and $C P<0.01$ : Lean vs obese black.

$\mathrm{d} P<0.05$ and $\mathrm{D} P<0.01$ : Lean vs. obese white.

In normal-weight subjects, there were no significant ethnic differences in VAT or total SAT areas. However, obese black women had significantly greater SSAT $(325.1 \pm 14.8$ vs. $\left.247.3 \pm 15.4 \mathrm{~cm}^{2}, \mathrm{p}<0.01\right)$ and significantly less VAT $(98.4 \pm 11.3$ vs. 147.2 $\pm 11.8, \mathrm{~cm}^{2}, \mathrm{p}<0.05$ ) compared with obese white women. No significant ethnic differences in deep SAT were observed $(269.9 \pm 14.3$ vs. $247.9 \pm 14.3, p=0.92)$. Obese black women also had significantly greater gynoid fat than obese white women when adjusted for age and total fat mass $(4.09 \pm 0.18$ vs. $3.54 \pm 0.2 \mathrm{~kg}$, respectively, $p$ $=0.043$ ).

\section{Blood Pressure}

None of the women were hypertensive, but obese women had significantly higher diastolic blood pressures compared to the lean group $(p<0.01)$ (table 2$)$. There were no ethnic differences in either systolic or diastolic pressures.

\section{Insulin Sensitivity and Associations with Abdominal Fat Depots}

Fasting glucose levels did not differ between ethnic and BMI groups (Table 3) and all subjects had normal glucose tolerance according to American Diabetes Association Criteria (published by Genuth, 2003).

The obese groups had a significantly greater fasting serum insulin concentration $(\mathrm{p}<0.01)$ and correspondingly lower IS ( $p$ $<0.01$ ) than the lean groups (Table 3).

Interestingly, both the lean and the obese black women had significantly lower IS ( $\mathrm{p}<$ 0.01 ) than their white counterparts (Table 3). 
Table 3. Metabolic parameters

\begin{tabular}{|c|c|c|c|c|}
\hline & $\begin{array}{c}\text { Lean Black } \\
\quad(n=14)\end{array}$ & $\begin{array}{l}\text { Lean White } \\
\qquad(n=13)\end{array}$ & $\begin{array}{l}\text { Obese Black } \\
\qquad(n=14)\end{array}$ & $\begin{array}{l}\text { Obese } \\
\text { White } \\
(n=13)\end{array}$ \\
\hline \multicolumn{5}{|c|}{ Glucose tolerance and insulin sensitivity } \\
\hline Fasting glucose (mmol/li) & $4.4 \pm 0.1$ & $4.3 \pm 0.1$ & $4.6 \pm 0.1$ & $4.6 \pm 0.1$ \\
\hline Fasting insulin $(\mathrm{mU} / \mathrm{I})$ & $8.2 \div 1.3$ & $4.2 \pm 1.3$ & $14.9 \pm 1.3^{\mathrm{mc}}$ & $8.7 \pm 1.3^{\prime}$ \\
\hline $\mathrm{IS}\left(\times 10^{-4} \mathrm{~min} / \mu \mathrm{U} / \mathrm{ml}\right)$ & $2.8 \pm 0.5 \mu c$ & $6.1 \pm 0.5 \times 0$ & $1.8 \pm 0.5 \times c$ & $3.8 \div 0.5=0$ \\
\hline \multicolumn{5}{|l|}{ Lipid profile } \\
\hline FFA $(\mathrm{mmol} / \mathrm{l})$ & $0.36 \pm 0.04$ & $0.35 \simeq 0.04$ & $0.40 \div 0.04$ & $0.46 \pm 0.04$ \\
\hline Triglycerides (mmol/l) & $0.61 \pm 0.08$ & $0.82 \pm 0.09$ & $0.82 \div 0.08^{*}$ & $0.90 \div 0.09 \varepsilon$ \\
\hline Total cholesterol $(\mathrm{mmol} / \mathrm{l})$ & $3.6 \div 0.3$ & $4.1 \pm 0.3^{4}$ & $3.8 \pm 0.3=$ & $5.0 \pm 0.3^{2 n .4}$ \\
\hline HDL-cholesterol (mmol/li) & $1.3 \pm 0.1 *$ & $1.8 \pm 0.1^{*}$ & $1.1 \neq 0.1^{\circ}$ & $1.6 \pm 0.1^{\circ}$ \\
\hline LDL-cholesterol $(\mathrm{mmol} / \mathrm{I})$ & $2.0 \pm 0.2$ & $1.9 \div 0.3^{4}$ & $2.3 \pm 0.2$ & $2.9 \pm 0.3^{t}$ \\
\hline \multicolumn{5}{|l|}{ Circulating Adipokines } \\
\hline Adiponectin $(\mathrm{ng} / \mathrm{ml})$ & $6.6 \pm 0.7 c$ & $6.8 \pm 0.7^{4}$ & $3.8 \pm 0.7 c$ & $4.1 \pm 0.70$ \\
\hline Leptin $(\mathrm{ng} / \mathrm{ml})$ & $15.3 \div 3.3^{c}$ & $18.8 \pm 3.4^{\circ}$ & $57.7 \pm 3.3^{c}$ & $50.9 \pm 3.4^{\circ}$ \\
\hline hsCRP $(\mu \mathrm{g} / \mathrm{ml})$ & $2.8 \pm 0.8$ & $1.4 \pm 0.8^{\circ}$ & $6.1 \pm 0.8$ & $6.4 \pm 0.8^{\circ}$ \\
\hline IL-18 (pg/ml) & $167.3 \pm 44.8$ & $170.7 \div 20.0$ & $174.5=37.8$ & $279.6 \pm 28.6$ \\
\hline \multicolumn{5}{|c|}{$\begin{array}{l}\text { Values are unadjusted mean } 2 \text { SEM. All } P \text { values adjusted for age. } \\
\text { a } P<0.05 \text { and } A P<0.01 \text { : Lean black vs. Lean white. } \\
b P<0.05 \text { and } B P<0.01 \text { : Obese black vs. obese white. } \\
c P<0.05 \text { and } C P<0.01 \text { : Lean vs. obese black. } \\
d P<0.05 \text { and } D P<0.01 \text { : Lean vs. obese white. }\end{array}$} \\
\hline
\end{tabular}

In both black and white women, DSAT (whites $\mathrm{R}=-0.55, \mathrm{p}<0.01$, blacks $\mathrm{R}=-0.59$, $\mathrm{p}<0.01$ ) and SSAT (whites $\mathrm{R}=-0.55, \mathrm{p}<$ 0.01 , blacks $\mathrm{R}=-0.50, \mathrm{p}=0.01$ ) were significantly negatively correlated with IS. In contrast, VAT was significantly negatively correlated with IS in white but not black women (white $\mathrm{R}=-0.53, \mathrm{p}<0.01$, black $\mathrm{R}=$ $-0.31, \mathrm{p}=0.13$ ). In addition, gynoid (gluteal) fat mass was negatively associated with IS ( $R=-0.46, p=0.03$ ) in black but not white women $(\mathrm{R}=0.28, \mathrm{p}=0.22)$. In contrast, hip circumference was positively associated with IS in white women $(\mathrm{R}=$ $0.45, \mathrm{p}=0.044$ ) rather than black women $(\mathrm{R}=-0.01, \mathrm{p}=0.96)$. There were no significant associations between leg fat mass and IS in either ethnic groups.

\section{Lipids}

Obese white women had higher total cholesterol ( $p<0.01)$, HDL cholesterol $(p<$ $0.01)$ and TAG $(\mathrm{p}<0.01)$ compared with obese black women. There was no significant ethnic difference in LDL (Table 3).

\section{Adipoctokines}

\section{Circulating Levels}

There were no significant ethnic differences in the levels of circulating adiponectin, leptin, hsCRP or IL-18, after adjusting for age (Table 3). However, adiponectin levels were lower ( $p<0.01)$, while leptin ( $\mathrm{p}<0.01)$ and hsCRP (p < 0.01 ) levels were higher in the obese compared with lean subjects. Plasma IL-18 did not differ in lean vs. obese groups after correction for age (Table 3). Circulating adiponectin ( $r=0.49, \mathrm{p}=0.045)$, leptin ( $\mathrm{r}=$ -0.62, $\mathrm{p}=0.007)$ and hsCRP ( $\mathrm{r}=-0.59, \mathrm{p}=$ 0.002 ) levels were significantly associated with IS in white, but not black women (adiponectin: $\mathrm{r}=0.03, \mathrm{p}=0.86$; leptin: $\mathrm{r}=$ $0.15, \mathrm{p}=0.44$; CRP: $\mathrm{r}=-0.17, \mathrm{p}=0.35$ ). 


\section{Tissue mRNA Levels}

Leptin mRNA levels correlated significantly with circulating leptin levels in all fat depots (DSAT: $r=0.72, p<0.001$; SSAT: $r=$ 0.73, $\mathrm{p}<0.001$; Gluteal: $\mathrm{r}=0.61, \mathrm{p}<0.001$ ). Similarly, adiponectin mRNA levels correlated significantly with circulating adiponectin levels in all fat depots (DSAT: $r$ $=0.56, p<0.001$; SSAT: $r=0.63, p<0.001$; Gluteal depot in blacks: $r=0.72, p<0.001$ ) except the gluteal depot of whites $(\mathrm{r}=0.26$, $\mathrm{p}=0.196)$. In contrast, IL-18 mRNA levels did not correlate with circulating levels (data not shown).

With obesity, adiponectin mRNA levels decreased significantly while leptin and IL18 mRNA levels increased significantly in all fat depots (SSAT, DSAT and gluteal; $\mathrm{p}<$ 0.001). Only leptin mRNA levels showed a significant ethnic difference (after being adjusted for age) being higher in black women in all three depots $(\mathrm{p}<0.001)$ (figure 1).
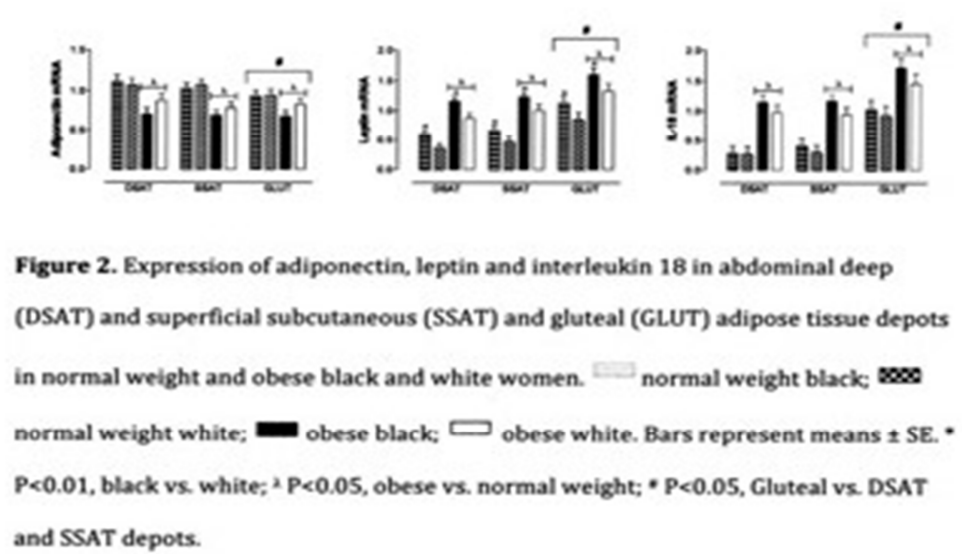

Leptin and IL-18 mRNA levels, were higher in the gluteal than in either DSAT or SSAT depots $(p<0.001)$, whereas gluteal adiponectin mRNA levels were lower in the gluteal than the DSAT or SSAT depots ( $\mathrm{p}<$ 0.001 ) in both ethnic groups.

\section{Tissue mRNA Levels and Associations with IS}

After adjusting for age and fat mass, only gluteal adiponectin mRNA levels $(r=0.44$, $p=0.03$ ) in black women were associated with IS. In white women, IS was associated with SSAT leptin mRNA levels $(\mathrm{r}=-0.54, \mathrm{p}=$ 0.01 ) and IL-18 mRNA levels in all fat depots $(\mathrm{p}<0.001)$ (data not shown).

\section{Discussion}

With the realization that adipose tissue is metabolically active, the hypothesis that the benefits of liposuction may go beyond aesthetics and the patient's self-esteem began to be tested. Several prospective clinical trials (Table 1) have examined the effects of LVL on IS, dyslipidaemia, and the inflammatory and adipokine profiles, but the results of these trials are conflicting. Although the clinical status of the patients, technique of IS measurement, volume of fat aspirated, changes in diet or exercise regimes, and duration of follow-up may account for the variable outcomes of these trials, the present study has highlighted several other important factors.

We examined the ethnic specific variations in the distribution of adipose tissue and the associations between these fat depots and IR and CV risk factors. In this regard, we found that obese black women were more IR, but accumulated more SSAT compared with obese white women who accumulated more VAT. Further, VAT in white women was associated with decreasing IS; but this was not the case in black women. Rather, SAT, both deep and superficial SAT depots, were associated with decreasing IS in both black and white women. These findings are supported by Lovejoy et al. (1996) who found that African American women 
accumulate more SAT and less VAT than Caucasian women, and that SAT and not VAT was associated with decreased IS in African American women.

In addition, we found that obese black women accumulate significantly more gynoid or gluteal fat than white women. Several studies (including those by Manolopoulos et al., 2010; Porter et al., 2009; Snijder et al., 2004; Lissner et al., 2001) described gluteofemoral fat (as measured by thigh circumference, hip circumference and DXA determined thigh adipose tissue mass) as exerting specific functional properties that are associated with an improved metabolic and CV risk profile. Lemieux (2004) suggested that this protective effect may be a result of peripheral fat having high lipoprotein lipase activity and low fatty acid turnover, thereby acting as a "metabolic sink" for the accumulation of excessive plasma lipids.

Many of these cross sectional studies were however performed in European countries where the relative proportion of black patients may have been small. In contrast, a recent study by Bays et al. (2010), in a mixed ethnicity patient cohort, has shown an increased risk of type 2 diabetes with an increase in the hip circumference.

Notably, a novel finding of the present study is that the gluteal fat depot was associated with decreasing IS in black women only. On the contrary, an increase in the hip circumference in white women was associated with improved IS (i.e. a protective profile).

This may be explained by their different adipocytokine expression profiles (figure 1), with higher IL-18 and leptin mRNA levels in black compared with white women, particularly in the gluteal depot (although only leptin mRNA showed significant ethnic variability after being adjusted for age). Havel (2004) and Eposito et al. (2006) showed that increased secretion of leptin in obesity is associated with decreased insulin sensitivity and hypertension. Elevated IL-18 on the other hand, is proatherogenic (Skurk et al., 2005) and is also associated with myocardial dysfunction (Woldbaek et al., 2005) and the development of IR, independent of obesity (Hung et al., 2005). However, only the gluteal adiponectin mRNA levels in black women, and IL-18 mRNA levels and SSAT leptin mRNA levels in white women, were associated with IS.

There are several limitations to this study. Firstly, the number of participants, in each ethnic group and weight category, was relatively small. Also, they were not randomly selected and our cohort may therefore not be representative of the entire population. Similarly, we only measured a few adipocytokines, although numerous other important adipocytokines have been described. In addition, the gynoid area of interest was measured using the standard DXA technique described by Let et al. (1992), although a CT/ MRI scan may be a more accurate measure of fat in this depot.

\section{Conclusion}

In conclusion, it is found that black women are more IR than their white counterparts. In addition, obese black women accumulate more SSAT and less VAT than obese white women. VAT in white women was associated with decreasing, IS which is not the case in black women. However, SSAT and DSAT were negatively associated with IS in both ethnic groups. Based on these findings, we propose that a reduction in the volume of abdominal SAT (either SSAT or DSAT) by LVL may improve IS in both ethnic groups. As obese black women accumulate more SSAT (and therefore SAT) , they may however benefit more (in terms of improvement in IS, metabolic profile and cardiovascular risk factors) than obese white women.

Further, we found that the gluteal area has the highest levels of adipocytokine mRNA in both white and black women, but it has variable ethnic associations with IS. In this regard, liposuction of the gluteal area may improve the metabolic profile in black women, but may worsen the IR in white women. 
We recommend that future prospective trials examining the metabolic effects of LVL in obesity be stratified according to ethnicity as well as gluteal vs. abdominal depots.

\section{Acknowledgements}

The authors thank the research volunteers for their participation in this study. Sacha West, thanks are due to Hendriena Victor and Judy Belonje for their expert technical assistance. The authors also thank Dr Jack Bergman and Naomi Fenton of Symington Radiology for performing the CT scans, Linda Bewerunge for performing the DXA scans, and Dr Kevin Adams for his help with the fat biopsies.

\section{Funding}

This study was funded by the Medical Research Council of South Africa, the International Atomic Energy Agency, the National Research Foundation of South Africa and Royal Society SA-UK Science Networks Programme, and the University of Cape Town.

\section{Disclosure}

The authors declare no conflict of interest.

\section{References}

Abate, N., Garg, A., Peshock, R. M. \& StrayGundersen, J. (1995). "Relationship of Generalized and Regional Adiposity to Insulin Sensitivity in Men," J Clin Invest, 96, 88-98.

Abate, N., Garg, A., Peshock, R. M., StrayGundersen, J., Adams-Huet, B., Grundy, S. M. (1996). "Relationship of Generalized and Regional Adiposity to Insulin Sensitivity in Men with NIDDM," Diabetes, 45, 1684-93.

Barzalai, N., She, L., Liu, B. Q., Vuguin, P., Cohen, P., Wang, J. \& Rossetti, L. (1999). "Surgical Removal of Visceral Fat Reverses Hepatic Insulin Resistance," Diabetes, 48, 94-8.
Bassetto, F., Gharb, B. B., Rampazzo, A., Busetto, L., Pigozzo, S. \& Nolli, M. (2005). "Reply to: Effect of Liposuction on Insulin Resistance and Vascular Inflammatory Markers in Obese Women," Br J Plast Surg.

Bays, H. E. (2009). ""Sick Fat", Metabolic Disease, and Atherosclerosis," Am J Med, 122 (1A), S26-S37.

Bays, H. E., Fox, K. M. \& Grandy, S. (2010). "Anthropometric Measurements and Diabetes Mellitus: Clues to the "Pathogenic" and "Protective" Potential of Adipose Tissue," Meta Synd and Related Disorders, 8 (4), 307-15.

Bays, H. E., Gonzalez-Campoy, J. M., Bray, G. A. et al. (2008). "Pathogenic Potential of Adipose Tissue and the Metabolic Consequences of Adipocytes Hypertrophy and Increased Visceral Adiposity," Expert Rev. Cardiovasc Ther, 6 (3), 343-368.

Bergman, R. N., Ider, Y. Z., Bowden, C. R. et al. (1979). "Quantitative Estimation of Insulin Sensitivity," American J Physiol, 236, E667-E677.

Carey, D. G., Jenkins, A. B., Campbell, L. V., Freund, J. \& Chrisholm, D. J. (1996). "Abdominal Fat and Insulin Resistance in Normal and Over-Weight Women: Direct Measurements Reveal a Strong Relationship in Subjects at Both Low and High Risk of NIDDM," Diabetes, 45, 633-8.

Colberg, S. R., Simoneau, J.- A., Thaete, F. L. \& Kelley, D. E. (1995). "Skeletal Muscle Utilization of Free Fatty Acids in Women with Visceral Obesity," J Clin Invest 95, 1427-28.

D'Andrea, F., Girella, R., Rizzo, M. R., Grella, E., Grella, R., Nicoletti, G., Barbieri, M. \& Paolisso, G. (2005). "Changing the Metabolic Profile by Large Volume Liposuction: A Clinical Study Conducted with 123 Obese Women," Aesth Pl Surg, 29, 472-478. 
Esposito, K., Giugliano, G. \& Giugliano, D. (2004). "Metabolic Effects of LiposuctionYes or No?," Letter to the Editor, N Engl J Med, 351 (13), 1354-56.

Esposito, K., Giugliano, G., Nicolo, S. \& Dario, G. (2006). "Role of Adipokines in the Obesity-Inflammation Relationship: The Effect of Fat Removal," Plast Recon Surg, 118 (4), 1048-57.

Finucane, M. M., Stevens, G. A., Cowan, M. J. et el. (2011). "National, Regional, and Global Trends in Body-Mass Index Since 1980: Systematic Analysis of Health Examination Surveys and Epidemiological Studies with 960 Country-Years and 9•1 Million Participants," Lancet, 377 (9765), 557-567.

Genuth, S., Alberti, K. G., Bennett, P. et el. (2003). "Follow-Up Report on the Diagnosis of Diabetes Mellitus," Diabetes Care, 26, 3160-3167.

Giese, S. Y., Bulan, E. J., Commons, G. W. et al. (2001). "Improvements in Cardiovascular Risk Profile with Larger Volume Liposuction: A Pilot Study," Plast Reconstr Surg, 108 (2), 510-519.

Giugliano, G., Nicoletti, G., Grella, E. et al. (2004). "Effects of Liposuction on Insulin Resistance and Vascular Inflammatory Markers in Obese Women," Br J Pl Surg, 57, 190-94.

Goedecke, J. H. el al (2009). "Differential Effects of Abdominal Adipose Tissue Distribution on Insulin Sensitivity in Black and White South African Women," Obesity: 1506-12.

Goedecke, J. H., Wake. D. J., Levitt, N. S. et al. (2006). "Glucocorticoid Metabolism with Superficial Subcutaneous Rather Than Visceral Adipose Tissue Is Associated with Features of the Metabolic Syndrome in South African Women," Clin Endocrinology, $65,81-87$.

Gonzalez-Ortiz, M., Robles-Cervante, J., Cardenas-Camarena, L. et al. (2002). "The Effects of Surgically Removing Subcutaneous Fat on the Metabolic Profile and Insulin Sensitivity in Obese Women after Large Volume Liposuction Treatment," Horm Metab Res, 34, 446-9.

Goodpaster, B. H., Thaete, F. L., Simoneau, J.A. \& Kelly, D. E. (1997). "Subcutaneous Abdominal Fat and Thigh Muscle Composition Predict Insulin Sensitivity Independently of Visceral Fat," Diabetes, 46, 1579- 1585.

Greenberg, A. S. \& Obin, M. S. (2006). "Obesity and the Role of Adipose Tissue in Inflammation and Metabolism," Am J Clin Nutr, 83 (Suppl), 461S-465S.

Havel, P. J. (2004). "Lipid Modulators of Islet Cell Function. Update on Adipocyte Hormones and Regulation of Energy Balance and Carbohydrate/Lipid Metabolism," Diabetes, 53, S143-S151.

Hung, J., Mcquillan, B. M., Chapman, C. M. L., Thompson, P. L. \& Beilby, J. P. (2005). "Elevated IL-18 Levels Are Associated with the Metabolic Syndrome Independent of Obesity and Insulin Resistance," Arterioscler Thromb Vasc Biol, 25, 1268-73.

Janssen, I., Katzmarzyk, P. T. \& Ross, R. (2004). "Waist Circumference and Not Body Mass Index Explains Obesity-Related Health Risk," Am J Clin Nutr, 79, 379-84.

Joffe, B. I. \& Seftel, H. C. (1994). "Diabetes Mellitus in the Black Communities of Southern Africa," J Int Med, 235, 137-142.

Kelly, D. E. (2004). "Thermodynamics, Liposuction, and Metabolism," $N$ Engl J Med, 350 (25), 2542-44.

Kelly, D. E., Thaete, F. L., Troost, F. et al. (2000). "Subdivisions of Subcutaneous Abdominal Adipose Tissue and Insulin Resistance," Endocrinal Metab, 278, E941948.

Klein, S. (2004). "The Case of Visceral Fat: Argument for the Defense," J Clin Invest, 113 (11), 1530-2.

Klein, S., Fontana, L., Young, L. et al. (2004). "Absence of an Effect of Liposuction on Insulin Action and Risk Factors for 
Coronary Heart Disease," N Engl J Med, 350 (25), 2549-557.

Lago, F., Dieguez, C., Gomez-Reino, J. \& Gualillo, O. (2007). "Adipokines as Emerging Mediators of Immune Response and Inflammation," Rheumatology, 3 (12), 716-24.

Lebowitz, H. E. \& Banerji, M. A. (2005). "Point: Visceral Adiposity Is Causally Related to Insulin Resistance," Diabetes Care, 28 (9), 2322-325.

Lemieux, I. (2004). "Energy Partitioning in Gluteal-Femoral Fat: Does the Metabolic Fate of Triglycerides Affect Coronary Heart Disease Risk?," Arterioscler Thromb Vasc Biol, 24 (5), 795-7.

Ley, C. J., Lees, B. \& Stevenson, J. C. (1992). "Sex- and Menopause-Associated Changes in Body-Fat Distribution," Am J Clin Nutr, 55 (5), 950-4.

Lissner, L., Bjorkelund, C., Heitmann, B. L., et al. (2001). "Larger Hip Circumference Independently Predicts Health and Longevity in a Swedish Female Cohort," Obes Res, 9 (10), 644-6.

Lovejoy, J. C., De La Bretonne, J. A., Klemperer, M. \& Tulley, R. (1996). "Abdominal Fat Distribution and Metabolic Risk Factors: Effects of Race," Metabolism, 45, 1119-124.

Manolopoulos, K. N., Karpe, F. \& Frayn, K. N. (2010). "Gluteofemoral Body Fat as a Determinant of Metabolic Health," Int $J$ Obesity: 1-11.

Misra, A., Garg, A., Abate, N., Peshock, R. M., Stray-Gundersen, J. \& Grundy, S. M. (1997). "Relationship of Anterior and Posterior Subcutaneous Abdominal Fat to Insulin Sensitivity in Nondiabetic Men," Obes Res, 5, 93-99.

Mohammed, B. S., Cohen, S., Reeds, D., Young, V. L. \& Klein, S. (2008). "Long Term Effects of Large-Volume Liposuction on Metabolic Risk Factors for Coronary Heart Disease," Obesity, 16 (12), 2648-651.
Nazare, J. A., Smith, J. D., Borel, A. L. et al. (2012). "Ethnic Influences on the Relationship Between Abdominal and Visceral Adiposity, Liver Fat, and Cardiometabolic Risk Profile: The International Study of Prediction of IntraAbdominal Adiposity and Its Relationship with Cardiometabolic Risk/IntraAbdominal Adiposity," Am J Clin Nutr.

Perez, R. A. (2007). "Liposuction and Diabetes Type 2 Development Risk Reduction in the Obese Patient," Medical Hypotheses, 68, 393-96.

Porter, S. A., Massaro, J. M., Hoffmann, U., Vasan, R. S., O'Donnell, C. J. \& Fox, C. S. (2009). "Abdominal Subcutaneous Adpose Tissue: A Protective Fat Depot?," Diabetes Care, 32, 1068-75.

Pries, S. R., Massaro, J. M., Robins, S. J., et al. (2010). "Abdominal Subcutaneous and Visceral Adipose Tissue and Insulin Resistance in the Framington Heart Study," Obesity, 18 (11), 2191-2198.

Punyadeera, C., van der Merwe, M.- T., Crowther, N. J., Toman, M., Immelman, A. R., Schlaphoff, G. P. \& Gray, I. P. (2001). "Weight-Related Differences in Glucose Metabolism and Free Fatty Acid Production in Two South African Population Groups," Int J Obes Relat Metab Disord, 25, 11961205.

Punyadeera, C., van der Merwe, M.- T., Crowther, N. J., Toman, M., Schlaphoff, G. P. \& Gray, I. P. (2001). "Ethnic Differences in Lipid Metabolism in Two Groups of Obese South African Women," J Lipid Res, 42, 760767.

Robles-Cervantes, J. A., Yanez-Diaz, S. \& Cardenas-Camarena, L. (2004). "Modification of Insulin, Glucose and Cholesterol Levels in Nonobese Women Undergoing Liposuction. Is Liposuction Metabolically Safe?," Ann Plast Surg, 52 (1), 64-7.

Schutte, A. E., Huisman, H. W., Van Rooyen, J. M. et al. (2008). "Should Obesity Be Blamed for the High Prevalence Rates of Hypertension in Black South African Women?," J Hum Hypertens, 22 (8), 528-36. 
Seedat, Y. K. (1983). "Race, Environment and Blood Pressure: The South African Experience," J Hypertens, 1, 7-12.

Skurk, T., Kolb, H., Muller-Scholze, S. et al. (2005). "The Proatherogenic Cytokine IL18 Is Secreted by Human Adipocytes," Eur J of Endocrinol, 152, 863-68.

Snijder, M. B., Zimmet, P. Z., Visser, M. et al. (2004). "Independent and Opposite Associations of Waist and Hip Circumferences with Diabetes, Hypertension and Dyslipidemia: The Ausdiab Study," Int J Obes Relat Metab Disord, 28 (3), 402-9.

Sumner, A. E. (2008). "The Relationship of Body Fat to Metabolic Disease: Influence of Sex and Ethnicity," Gend Med., 5 (4), 361-71.

Walker, G. E., Verti, B., Marzullo, P., et al. (2007). "Deep Subcutaneous Tissue: A Distinct Abdominal Adipose Depot," Obesity, 15 (8), 1933-943.

Wei, M., Gaskill, S. P., Haffner, S. M. \& Stern, M. P. (1997). "Waist Circumference as the Best Predictor of Noninsulin Dependant Diabetes (NIDDM) Compared to Body Mass Index, Waist/Hip Ratio and Other Anthropometric Measurements in Mexican Americans: A 7-Year Prospective Study," Obes Res., 5, 16-23.

Wold Baek, P. R., Sande, J. B., Stromme, T. A. et al. (2005). "Daily Administration of Interleukin-18 Causes Myocardial Dysfunction in Healthy Mice," Am J Physiol Heart Circ. Physiol, 289, H708-714. 